\title{
Floristic mapping data as a proxy for the mean urban heat island
}

\author{
Benjamin Bechtel $^{1, *}$, Katharina Johanna Schmidt ${ }^{2}$ \\ ${ }^{1}$ Institute of Geography, University of Hamburg, Bundesstr. 55, Hamburg, Germany \\ ${ }^{2}$ Biocenter Klein Flottbek, University of Hamburg, Ohnhorststr. 18, Hamburg, Germany
}

\begin{abstract}
Assessment of spatial variability in the long-term urban heat island (UHI) is severely restricted by coverage and availability of measurements. This also limits the opportunities to analyse its relation to surface characteristics. In this study we therefore introduce a new proxy dataset derived from floristic mapping. The basic assumption is that the species composition in an area reflects climatologic conditions of a certain time period. Ellenberg indicator values for temperature (EITs) were processed to summarise the overall temperature preferences of the occurring plant species. The EITs showed a clear heat island pattern, were highly correlated with existing measurements, and showed increased values in densely built urban classes. Hence, they are considered suitable as UHI proxies. Further, they were related to a large number of typical UHI predictors. The normalised difference vegetation index (NDVI) showed the strongest correlation with the derived pattern and was comparatively robust towards cloud contamination. Urban morphology also explained a noticeable proportion of the overall variance. All predictors explained more than $2 / 3$ of the overall spatial variability, while the redundancy was high. Therefore, the predictors at least allow qualitative statements about the differential exposure to heat-related risks in cities.
\end{abstract}

KEY WORDS: Floristic mapping · Urban heat island · Ellenberg indicator values · UHI predictors · Local climate zones $\cdot$ Infrared thermography

\section{INTRODUCTION}

The urban heat island (UHI) is the 'most obvious manifestation of urbanization' (Landsberg 1981, p. 83) and remains the most intensively studied climatic feature of cities (Oke 1973, 1988, Souch \& Grimmond 2006). The intensity of the UHI is usually defined as urban-rural air temperature difference, although the meanings of the terms urban and rural are somewhat blurred (Stewart \& Oke 2009). Published case studies cover a variety of towns, cities and metropolitan agglomerations on almost all continents, very different spatiotemporal scales and a broad methodological spectrum. Therefore, the UHI has been measured and analysed for virtually any period between a single night and a full century, which makes general conclusions difficult. Frequently used methodologi- cal approaches to characterise the UHI are comprised of measurements from meteorological stations and mobile sensors, numerical and physical modelling, and aerial and satellite remote sensing. Each of them has advantages and limitations in terms of coverage, spatial and temporal resolution as well as representativeness and accuracy. However, these studies suggest that observed air temperature differences between urban and rural areas as well as within cities depend on numerous factors and processes (e.g. Lowry 1977, Oke 1988, Matzarakis 2001, Souch \& Grimmond 2006, Hart \& Sailor 2009), which are partially indicated in the conceptual overview in Fig. 1.

Considering climate change and the likely increase of summer heat waves, the UHI, which can have human health and thermal comfort consequences (Hart \& Sailor 2009), will gain further importance, 


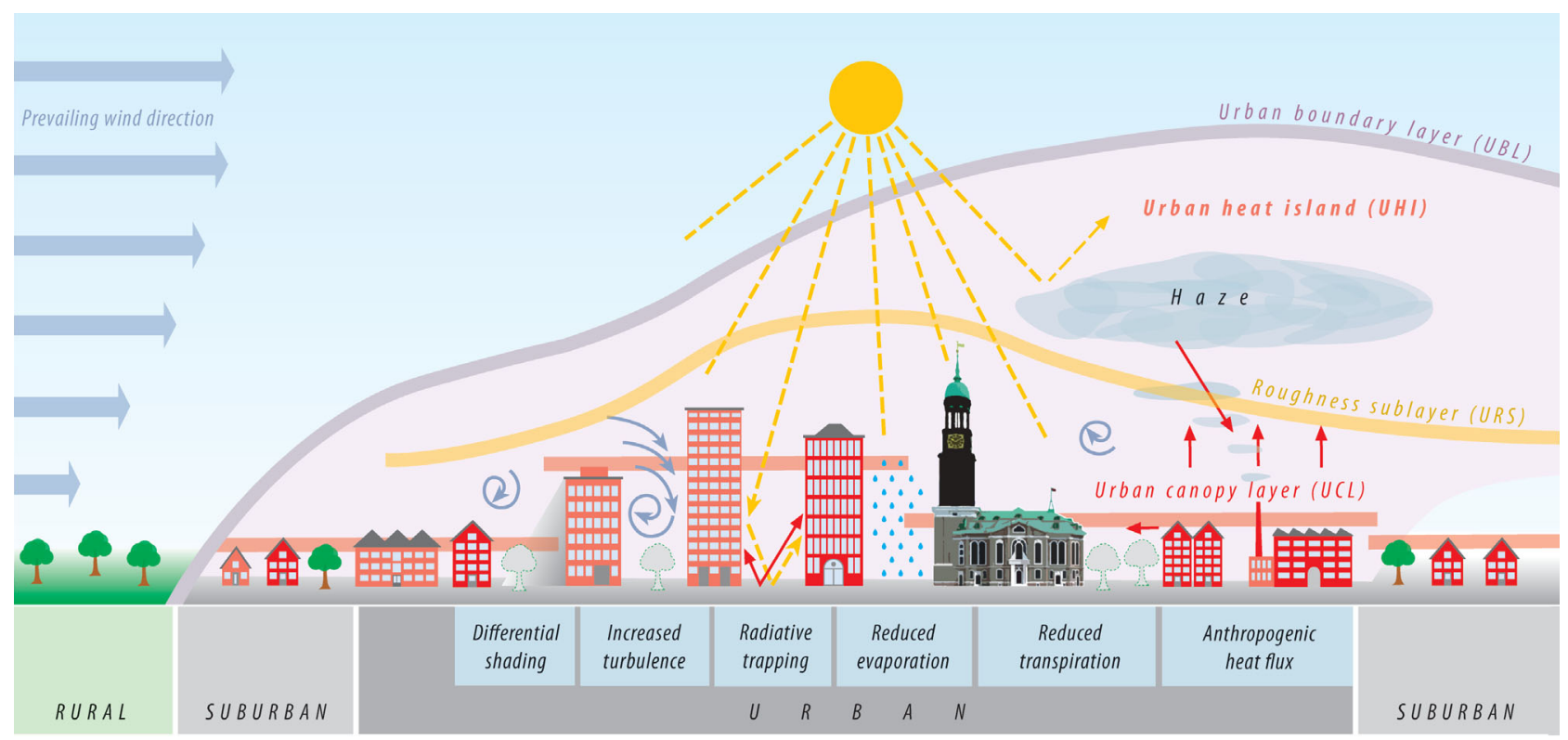

Fig. 1. Urban climate is a superposition of various effects and processes; adapted from Oßenbrügge \& Bechtel (2010)

even in a maritime climate. More detailed knowledge about the impact of different urban morphologies on mean air temperature would help to adapt urban infrastructures to climate change-related risks in time. However, the frequent lack of long-term UHI data severely limits such analysis.

We therefore examined a new proxy dataset, which has potential to indicate the mean annual to mean decadal heat island intensity for a whole city at a spatial resolution of $1 \mathrm{~km}$ in a consistent manner. This dataset was derived from the mapping of spontaneous occurring plant species in Hamburg, Germany, which was conducted over a period of $15 \mathrm{yr}$. The underlying idea is that the species composition in a certain area yields information about the respective climatic and ecological conditions (Ellenberg et al. 1992). Although this approach might be uncommon in urban climatology, it is appropriate considering the long tradition of phenology in urban climatology, especially in Hamburg (cf. Franken 1955). Gödde \& Wittig (1983) presented a thermal division of Münster, Germany, on a vegetational basis which visually represented typical zoning of urban microclimatic conditions. In this study we not only interpreted patterns from the floristic dataset visually, but also conducted an empirical analysis, and further refined the data as a proxy for UHI intensity.

To gain more detailed knowledge of the UHI intensity, its spatiotemporal structure and influencing factors, the UHI intensity is often related to different descriptors of the urban surface. These are more or less associated with some of the processes shown in
Fig. 1 (e.g. Oke 1973, Roth et al. 1989, Voogt \& Oke 2003, Bottyán et al. 2005, Nichol et al. 2009, Wong et al. 2009, Yokobori \& Ohta 2009). Another major motivation to relate descriptors of urban structures to air temperature is to assess and correct for urbanisation effects in long-term climate records for estimations of global near surface temperature and corresponding trends (Karl et al. 1988, Gallo et al. 1993, Gallo \& Owen 1999, Hansen et al. 2010, Parker 2010). Some of the most common predictors and selected case studies are listed in Table 1.

Our main hypothesis was that the plant species composition, and especially the percentage of thermophilic plants, yield relevant information about the longterm air temperature distribution within an urban agglomeration. Furthermore, we assumed that floristic data are suitable as a proxy for long-term climatic conditions in a city. We expected UHI predictors to be significantly correlated with the 'floristic heat island'.

The following research questions were posed:

(1) What information does the plant species composition contain about the long-term air temperature distribution within an urban agglomeration?

(2) Are the proxy data that are derived from plant species composition related to long-term air temperature measurements, and do the proxy data differ between areas with different urban morphological structures?

(3) Are the temperature proxy data derived from plant species composition related to common UHI predictors, and which predictors show the strongest correlation? 
Table 1. Predictors related to the urban heat island (UHI) in the literature and selected case studies

\begin{tabular}{|c|c|c|}
\hline Predictor class & Notes \& examples & Case studies \\
\hline Thermal imagery & Air- and spaceborne & $\begin{array}{l}\text { Eliasson (1992), Gallo et al. (1993), Gallo \& Owen (1998, 1999), } \\
\text { Roth et al. (1989), Voogt \& Oke (2003), Nichol et al. (2009), } \\
\text { Wong et al. (2009), Balázs et al. (2009) }\end{array}$ \\
\hline Vegetation & $\begin{array}{l}\text { Normalised difference } \\
\text { vegetation index (NDVI) }\end{array}$ & Gallo et al. (1993), Gallo \& Owen (1998, 1999), Wong et al. (2009) \\
\hline $\begin{array}{l}\text { Urban morphology } \\
\text { parameters }\end{array}$ & $\begin{array}{l}\text { Building density, building } \\
\text { height, soil sealing }\end{array}$ & $\begin{array}{l}\text { Kuttler et al. (1996), Bottyán et al. (2005), Alcoforado \& Andrade } \\
\text { (2006), Hart \& Sailor (2009), Wong et al. (2009), Buttstädt et al. (2010) }\end{array}$ \\
\hline Nightlight radiance & & Gallo \& Owen (1998), Hansen et al. (2010) \\
\hline Population & Absolute and density & Oke (1973), Karl et al. (1988), Hansen et al. (2010) \\
\hline $\begin{array}{l}\text { Vegetated area and } \\
\text { waterbodies }\end{array}$ & & $\begin{array}{l}\text { Alcoforado \& Andrade (2006), Yokobori \& Ohta (2009), Hart \& Sailor } \\
\text { (2009) }\end{array}$ \\
\hline Land use data & & Yokobori \& Ohta (2009), Hart \& Sailor (2009) \\
\hline Topoclimatic factors & E.g. altitude & Kuttler et al. (1996), Alcoforado \& Andrade (2006) \\
\hline
\end{tabular}

\section{DATA AND METHODS}

\subsection{City of Hamburg and regional climate}

The Free and Hanseatic City of Hamburg (53.55 $\mathrm{N}, 10.0^{\circ} \mathrm{E}$ ) is the second largest city in Germany with about 1.77 million inhabitants within the administrative borders and about 4.3 million in the metropolitan region.

In Hamburg, 4 distinctive natural regions converge: Saale glaciation moraines of Lüneburg Heath and Schleswig-Holstein, eastern Weichsel glaciation moraines and the glacial valley of the Elbe River - all leading to a high habitat diversity and therefore high plant species richness (Poppendieck et al. 2002). Water and especially the Elbe River are dominant landscape elements (water bodies cover $8 \%$ of Hamburg's area) with the characteristic harbour area (nearly $10 \%$ of the city's area). Furthermore, nature reserves comprise $8 \%$ of the area, preserving habitats like bogs, forests and grassland as well as the unique tidal floodplain forests. Nevertheless, $60 \%$ of the area is covered by settlement and traffic elements (Statistisches Bundesamt, www.statistik-portal.de/ statistik-portal/de_jb09_jahrtabf1.asp).

Hamburg covers an area of $755 \mathrm{~km}^{2}$ and is situated in the northern German lowlands about $80 \mathrm{~km}$ from the North Sea and $70 \mathrm{~km}$ from the Baltic Sea. Consequently, air temperature extremes are quite moderate (with a yearly mean of $9.0^{\circ} \mathrm{C}$ ) and mean wind speeds are comparably high (monthly means between 3.2 and $4.7 \mathrm{~m} \mathrm{~s}^{-1}$, Rosenhagen \& Schatzmann 2011). The urban climate in Hamburg has thus far been less thoroughly investigated than other cities. Reidat (1971) was the first to measure the UHI and discover a mean air temperature difference of $0.6 \mathrm{~K}$ in January and $1.0 \mathrm{~K}$ in July between meteorological stations in St. Pauli (a densely built district close to the inner city) and at the airport in Fuhlsbüttel in the periphery. Schlünzen et al. (2010) analysed the mean daily heat island of 5 stations in Hamburg and 1 station in Ahrensburg, a town close to Hamburg, for the decade between 1988 and 1997. They reported a mean heat island of $1.1 \mathrm{~K}$ for St. Pauli and $0.6 \mathrm{~K}$ for Fuhlsbüttel compared to a reference station in Grambek east of Hamburg. The mean heat island and further information about all stations is given in Table 2 .

\subsection{Floristic mapping data and Ellenberg indicators}

The flora of Hamburg was mapped for the past 15 yr (1995-2009) by the Botanischer Verein zu Hamburg e.V. (subsequently called Botanical Association). Presence and absence of all vascular plant species were recorded on a $1 \mathrm{~km}^{2}$ Gauß-Krüger zone 3 grid, a traditional German transverse Mercator projection. All grid cells were mapped repeatedly and at different times over the year (data set: Regionalstelle für Pflanzenartenschutz, Botanischer Verein zu Hamburg e.V. 2009). Altogether 1643 plant species (taxa) were registered (Poppendieck et al. 2010).

Based on the total list of the vascular plant species mapped, we generated a modified species list. We excluded non-established species (to obtain a longterm and relatively persistent floristic composition) as well as ornamental plants (to analyse only spontaneous vegetation). Furthermore, all tree and shrub species were excluded to avoid intentionally planted individuals. Aquatic plants were also eliminated, since they are expected to be more dependent on 
Table 2. Mean decadal heat island $(\mathrm{K})$ for the available stations (UHI $\mathrm{Utation}_{\text {) }}$ versus urban heat island derived from Ellenberg indicator values by linear regression $\left(\mathrm{UHI}_{\mathrm{EIT}}\right)$

\begin{tabular}{|llll|}
\hline Station & UHI $_{\text {station }}$ & UHI $_{\text {EIT }}$ & Surroundings / local climate zones \\
\hline Fuhlsbüttel & 0.58 & 0.48 & Airport \\
Kirchwerder & 0.69 & 0.76 & Agriculture and regular housing \\
Neuwiedenthal & 0.82 & 0.82 & Regular housing, partly commercial area \\
Sankt Pauli & 1.15 & 1.04 & Old core, compact housing and water \\
Wandsbek & 0.63 & 0.77 & Regular and compact housing \\
\hline
\end{tabular}

water temperature. The corresponding plant species were identified by linking the species data set with the BIOLFLOR database (Klotz et al. 2002), where the status of plant species as well as life form characteristics are available. The final species list consists of 902 vascular plant species (authors' unpubl. data).

Ellenberg indicator values describe the ecological behaviour of plants towards climatic and soil-related habitat conditions (Ellenberg et al. 1992). Each plant species is assigned an indicator value between 1 (low value) and 9 (high value). The Ellenberg indicator value for temperature (EIT) reflects the species' main geographical distribution and preferred position along the altitudinal gradient. The indicator values for temperature range from (1) indication of extremely cold conditions (e.g. plants from alpine altitudes), to (9) indication of extremely warm conditions (e.g. plants from the Mediterranean area). For the final set of species, mean EITs (EIT $m$ ) were calculated per cell of the original grid of the Botanical Association. Ellenberg indicator values are ordinal numbers and therefore do not fulfil the requirements for calculating arithmetic means. Nevertheless, the use of average indicator values is widely applied in vegetation ecology (Ellenberg et al. 1992, Ewald 2003, Petř́́k \& Wild 2006, Godefroid \& Koedam 2007). To control for potential errors, the percentages of 'thermophilic plants', which were defined to have an EIT of at least $6\left(\mathrm{EIT}_{>5}\right)$ by Gödde \& Wittig (1983), were generated. Overall, 625 species have distinct EITs and were included in the analysis.

EITs do not directly correspond to determined air temperature values, since they were not calibrated from measured temperature conditions in ecological experiments. Nevertheless, EITs are better related to physical environmental conditions than other Ellenberg indicator values like moisture, light or nitrogen (Ewald 2003). Ellenberg et al. (1992) also stated that there are strong correlations between mean indicator values for temperature and measured air temperatures as well as phenological observations.
Cities commonly have many established non-native plant species (e.g. Pyšek 1998). These species need to be considered when analysing indicator values for temperature in urban areas, because they often originate from warmer regions. Therefore, they might have higher EITs and thus contribute to increased mean indicator values per grid cell. We calculated the percentage of non-native species from the modified species list. The status of plant species (indigenous, pre-1500 non-native [first occurence in Germany before 1500] and post-1500 non-native [first occurence in Germany after 1500] was also available in the database BIOLFLOR (Klotz et al. 2002). Altogether we considered 103 non-native plant species ( $11.4 \%$ of the species set).

The time period of the floristic mapping of $15 \mathrm{yr}$ seems appropriate to reflect the climatic conditions in Hamburg, because major changes in species composition are not expected. For instance, Gödde \& Wittig (1983) stated that plants integrate climatic conditions over an extended period. Further, our species list contains only established species. Non-native species in particular require stable conditions for a considerable period of time for reproduction and spreading. The species set also includes annual species which might be considered as not very persistent. Nevertheless, they are usually rapid colonisers, and as cities are characterised by a high habitat turnover rate, new habitats are always available, so the main annual species composition per grid cell is not expected to change severely over time.

\subsection{Urban morphology data - local climate zones}

Local climate zones (LCZs, also thermal climate zones) were introduced by Stewart \& Oke (2009) to overcome the urban-rural dichotomy in urban climatology. They are defined as local-scale regions of relatively homogeneous air temperature in the canopy layer. A big advantage compared to rather qualitative older schemes is that Stewart \& Oke (2009) provided a hierarchical typology and a detailed fact sheet containing important quantitative features for every class. A disadvantage thus far is that although the authors intended to create a generic scheme without cultural biases, the classes are clearly related to north American urban morphologies. Therefore, Daneke et al. (2010) derived a more differentiated typology of European typical morpholo- 
gies that can be aggregated to the original LCZs. The authors digitised LCZ data from topographical maps and aerial imagery. In our study, we only used the original LCZ classes for the urban series.

\subsection{UHI predictors}

Regarding the selection of UHI predictors, special attention was given to remotely sensed and urban morphology parameters. The latter describe the urban form and can easily be linked to land use scenarios (Wong et al. 2009). The selected UHI predictors are the normalised difference vegetation index (NDVI), surface temperature $\left(T_{s}\right), 2$ parameters describing the annual cycle in $\mathrm{T}_{\mathrm{s}}$ (yearly amplitude of surface temperature, YAST; and mean annual surface temperature, MAST), nighttime city light (NIGHTLIGHT), land use (WATERSHARE, the percentage of the surface area comprising water bodies; SOILSEAL, the percentage of sealed surface area) and morphological characteristics (BUILDDENS, building density; GFZ, floor space index), positional and topographical parameters (ALTITUDE, SLOPE, ASPECT) as well as population density. These predictors are defined and described below, and a selection is shown in Fig. 2. All data were reprojected and resampled to the target grid of the Botanical Association using an area weighted average. Furthermore, water bodies were excluded from the remote sensing data (except NIGHTLIGHT), since they are not predominantly determined by the surface energy balance, and the vegetation inventory was conducted on land only.

Landsat data are freely available (datasets beginning in 1982). Landsat 4 and 5 carry the Thematic Mapper (TM), which has a 10.4 to $12.5 \mu \mathrm{m}$ thermal band in $120 \mathrm{~m}$ spatial resolution. Landsat 7 carries the Enhanced Thematic Mapper (ETM+) with a spatial resolution of $60 \mathrm{~m}$. We selected 36 scenes, excluding scenes with cloud contamination or scan line correction error. Hamburg is situated between 2 Landsat orbits (path 195 and 196). Landsat 5 and Landsat 7 cover the full area of Hamburg in 1 scene (row 23) for both paths. For Landsat 4, a small corner is missing in the north at path 196.
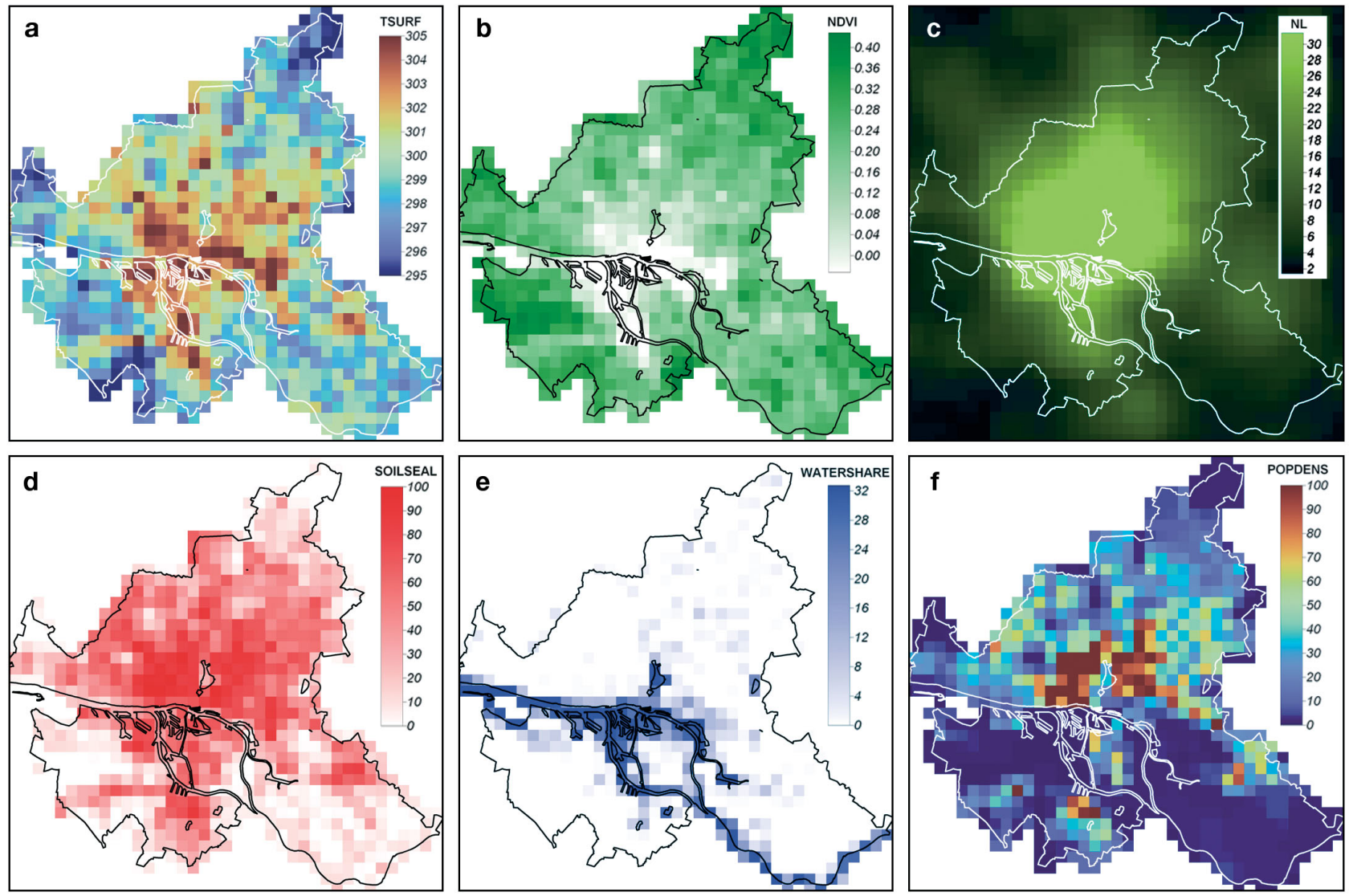

Fig. 2. Example predictors for Hamburg, Germany. (a) Surface temperature (K), (b) normalised difference vegetation index (NDVI); (c) NIGHTLIGHT radiance $\left(10^{-9} \mathrm{~W} \mathrm{~cm}^{-2} \mathrm{sr}^{-1}\right)$; (d) soil sealing; (e) water coverage (\%); (f) population density (inhabitants ha ${ }^{-1}$ ) 
We processed the scenes with the SAGA (Böhner et al. 2008, www.saga-gis.org) command line interpreter in a Perl script as follows. The digital numbers were calibrated to radiance, using the calibration constants delivered in the metadata and the procedure given by Chander et al. (2009). Atmospheric correction based on the radiative transfer code 'moderate resolution atmospheric transmission 4' (MODTRAN 4) was conducted with the National Aeronautics and Space Administration (NASA) atmospheric correction parameter calculator (Barsi et al. 2003, 2005) for 26 of the scenes.

To calculate the surface temperature, the emissivity $\varepsilon$ of the surface is needed. The moderate-resolution imaging spectroradiometer (MODIS) offers daily emissivity data at about $1 \mathrm{~km}$ resolution from a generalised split window approach for 2 bands (band 31: 10.78 to $11.28 \mu \mathrm{m}$, band 32: 11.77 to $12.27 \mu \mathrm{m})$, which together cover roughly half of the TM/ETM+ band. To evaluate the importance of spatial variability in $\varepsilon$, we analysed 1 scene (MOD11A2, version 5 from 15 May 2007). Within the Hamburg area, the emissivities for the 2 bands were $0.979 \pm 0.004(\mathrm{SD})$ and $0.983 \pm 0.003$, respectively. Hence, the spatial variability at the regarded scale is substantially smaller than the $2 \%$ given by Roth et al. (1989). Therefore, a constant emissivity was considered sufficient, and according to the MODIS data, $\varepsilon=0.98$ was chosen, which is slightly above typical values in the literature for urban areas (e.g. Landsberg 1981).

The long-term air temperature regime is influenced by dominant patterns of surface temperatures, rather than individual surface temperatures (seen at random acquisition times). The annual cycle of the 26 scenes is described by 2 parameters, MAST and YAST (Bechtel 2011).

The NDVI was calculated from the Landsat bands 3 (red) and 4 (near infrared, NIR) of the same scenes. Atmospheric correction was not considered necessary here, since the band ratio roughly compensates for atmospheric conditions as long as the adjacent bands are comparably affected.

The nighttime city light data (NIGHTLIGHT) represents the mean nighttime radiance from cloudfree images between March 1996 and February 1997. The dataset was taken from DMSP/OLS (Defense Meteorological Satellite Program/Operational Linescan System) data described by Imhoff et al. (1997) and has a spatial resolution of 30 arc seconds ( 900 $\mathrm{m})$. The data are freely provided by the National Oceanic and Atmospheric Administration (NOAA, www.ngdc.noaa.gov/dmsp/download_rad_cal_96-97. html).
For urban morphology parameters, the storeys were given a typical height, according to their period of construction and function. The subsequent parameters, BUILDDENS and floor space index, were derived from the buildings' area and number of storeys. The degree of soil sealing (SOILSEAL) was taken from the European Environment Agency Fast Track Service Precursor Sealing (Product 2, 'European Mosaic'). The percentage of water bodies (WATERSHARE) was taken from the above classification.

Furthermore, topographical and spatial parameters were included. The topographical parameters (especially altitude, slope and aspect) were calculated from the NASA Shuttle Radar Topography Mission (SRTM) dataset, which is freely available worldwide at a resolution of 3 arc seconds ( $\sim 90 \mathrm{~m})$. Furthermore, 2 parameters describing the relative position within the city were derived by distance transformation (Borgefors 1986). DIST2CEN describes the distance to the city centre, and DIST2MWB is the distance to the closest major water body. The population density was calculated from census data at the district level.

\subsection{Statistical analysis}

We had to assume a certain temporal persistence of the long-term UHI pattern, since station data, floristic mapping and predictors comprised different time spans. However, the UHI pattern can be expected to mostly depend on the shape of the urban fabric and therefore the change in urban morphology within the regarded timeframe can be considered. The urban land use was compared for the years 1990 and 2000 using digitised map data from Daneke et al. (2010). Regarding the settings around the climate stations, the assumption of persistence of urban morphology (and consequently negligible alterations of urban climate) was essentially confirmed by the data. For the whole city, the overall urban structure was mostly persistent in the relevant decade, although a few areas experienced distinct change. However, this remaining uncertainty is intrinsic to any study of urban climate, since urban structures tend to be dynamic and therefore never remain completely constant for a climatologically relevant time scale.

To assess whether the EITs contain substantial information about urban climate and UHI, we evaluated species distribution patterns and possible influence from other ecological factors. All analyses were conducted on the grid of the Botanical Association. Further, all grid cells with at least 100 species with EITs were taken into account, if not marked otherwise. 
To test the hypothesis that EITs reflect the inner urban long-term air temperature distribution, we calculated Pearson correlation coefficients as well as non-parametric Spearman rank correlation coefficients of EITs with the mean decadal UHI intensity data of Schlünzen et al. (2010) for the Hamburg stations. Therefore, each station was assigned to the respective cell in the $\mathrm{km}$ grid, even if it was not necessary in the centre or representative for the entire cell. For the control, a weighted average of surrounding cells was computed with comparable results. Since these data were only available for 5 stations, the sample size was very small.

For a comparison of the urban morphology on the EITs, they were evaluated for different LCZs. Differences in $\mathrm{EIT}_{\mathrm{m}}$ between the LCZ classes were analysed by a 1-way analysis of variance (ANOVA) followed by a Tukey-HSD post hoc test. On a km scale, subscale variation of land use is likely; therefore, each cell was assigned to an LCZ, if the dominant land use covered $\geq 75 \%$ of the area. This introduced additional variance to the classes but possibly also systematic errors due to typical class combinations. For instance, many agricultural cells contain built-up areas. Furthermore, the remaining area might include completely different habitats and therefore more than $25 \%$ of the species in the grid cell. The initial exclusion of tree and shrub species from the species list resulted in lower species numbers in forest areas than in other habitat types. To include forest areas as LCZs in the analysis, we only excluded grid cells with less than 80 species with EITs. The LCZ 'compact housing' was excluded from the analysis due to limited sample size.

To derive the floristic UHI pattern from the proxy data, a linear regression of the measured mean decadal UHI intensity with EIT $_{\mathrm{m}}$ was calculated. The obtained model was used to predict the heat island for the whole study area from the $\mathrm{EIT}_{\mathrm{m}}$. The predicted values were used in the subsequent analyses as UHI data. Here, an EIT subscript was added to the UHI pattern from the floristic proxy data $\left(\mathrm{UHI}_{\mathrm{EIT}}\right)$ for discrimination from the measured UHI intensity data. As this pattern is derived from mean decadal UHI intensity data by a linear regression model, a decade is roughly the time span it can be associated with, but its representativeness has to be considered with care. Since the $\mathrm{UHI}_{\mathrm{EIT}}$ values are calibrated with the measured UHI data and inherit any bias, the pattern is more reliable than the absolute numbers. Further, the determination of regression parameters is restricted by the sample size, and gradients in the derived pattern might differ somewhat. However, due to the linearity of the transformation, all further correlation results apply to $\mathrm{UHI}_{\mathrm{EIT}}$ and $\mathrm{EIT}_{\mathrm{m}}$ equally (explained variance is invariant against linear transformation).

To test the predictors, the pattern correlations (Santer et al. 1993) between UHI $\mathrm{EIT}_{\text {and common }}$ UHI predictors were calculated, which are essentially product moment correlations of the selected grid cells. For consistency, the same selection of grid cells (with at least 100 species) was used in this analysis, even where different predictors were related. Additionally, we conducted a multiple regression with the principal component of $13 \mathrm{z}$-transformed predictors to assess the overall explaining capacity and redundancy of the predictors. Here, a few cells had to be excluded due to missing values of single predictors.

\section{RESULTS AND DISCUSSION}

\subsection{Influence of further ecological factors in the EIT}

The spatial distribution of the EITs in Hamburg (see Fig. 4 for general pattern) suggests that the EITs contain substantial information about the urban climate and especially the UHI. The distribution follows the settlement structures and shows a concentric pattern, with high EITs in the city centre and decreasing values outwards. Besides climate, species distribution is certainly influenced by numerous factors, e.g. land use, soil conditions, disturbance, soil sealing or microclimatic conditions.

Furthermore, the distribution pattern of the proportion of non-native species is similar to that of the EITs. An increase of non-native species towards the city centre has also been detected in other studies (e.g. McKinney 2002). However, the solitary EITs of indigenous species also show a distinct UHI pattern, so the increased EITs in the city centre are not only due to more frequent occurrence of thermophilic non-native species.

Summarising, the EITs predominantly reflect the inner urban mean air temperature distribution, but to a certain degree also other ecological and climatic factors.

\subsection{Comparison of the EIT with available measurements}

Both the mean EIT of all species $\left(\right.$ EIT $\left._{m}\right)$ and the percentage of thermophilic plants $\left(\mathrm{EIT}_{>5}\right)$ were posi- 
tively correlated with the mean decadal UHI intensity. The Pearson correlation coefficients were 0.88 for $\mathrm{EIT}_{>5}$ and 0.89 for $\mathrm{EIT}_{\mathrm{m}}$. The respective Spearman rank correlation coefficients were 1.00 and 0.90 . Besides the small sample size, all correlations are significant. These strong relations are clear evidence that the species composition is sensitive to air temperature and that the EITs contain substantial information about the inner urban air temperature distribution. However, air temperature cannot exactly be specified as shelter height in this case, since many of the included plants are found in the ground vegetation layer, and therefore different air temperatures are integrated by the proxy data.

\subsection{Floristic thermal characteristics of LCZs}

The EIT $_{m}$ differed significantly between 3 classes of LCZs ( $p<0.001$; Fig. 3$)$. The results support the UHI interpretation of the EIT pattern, because urban classes showed greater mean EIT $_{\mathrm{m}}$ than agricultural classes. EIT $_{\mathrm{m}}$ of the LCZs old core and industry were significantly higher than EIT $_{\mathrm{m}}$ of the LCZs grassland, agriculture, and regular housing, while forest cells had significantly lower EIT $_{\mathrm{m}}$. Although compact housing was excluded from the analysis due to the small sample size, its mean was between regular housing and old core, which is consistent with increasing morphological density.

\subsection{Floristic heat island pattern from Ellenberg indicator values}

To determine the floristic heat island pattern, a linear regression model was fitted from EIT $_{\mathrm{m}}$ and long-term mean UHI measurements from station data (Schlünzen et al. 2010), resulting in the following empirical model: $\mathrm{UHI}_{\mathrm{EIT}}=2.15 \times \mathrm{EIT}_{\mathrm{m}}-11.56$. A comparison of the regression results from $\mathrm{EIT}_{\mathrm{m}}$ and the measured values of the mean decadal UHI for the 5 stations showed good agreement (Table 2). However, the sample size was small and no independent validation data are available. Hence, the determination of the regression parameters is limited. Further, the model cannot be directly transferred to other cities since it incorporates a specific regional climate.

The resulting 'floristic heat island' pattern from Ellenberg indicator values (UHI $\mathrm{EIT}_{\mathrm{E}}$ ) is shown in Fig. 4. The pattern shows greater $\mathrm{UHI}_{\mathrm{EIT}}$ in the densely built city core and harbour area with a radial decrease

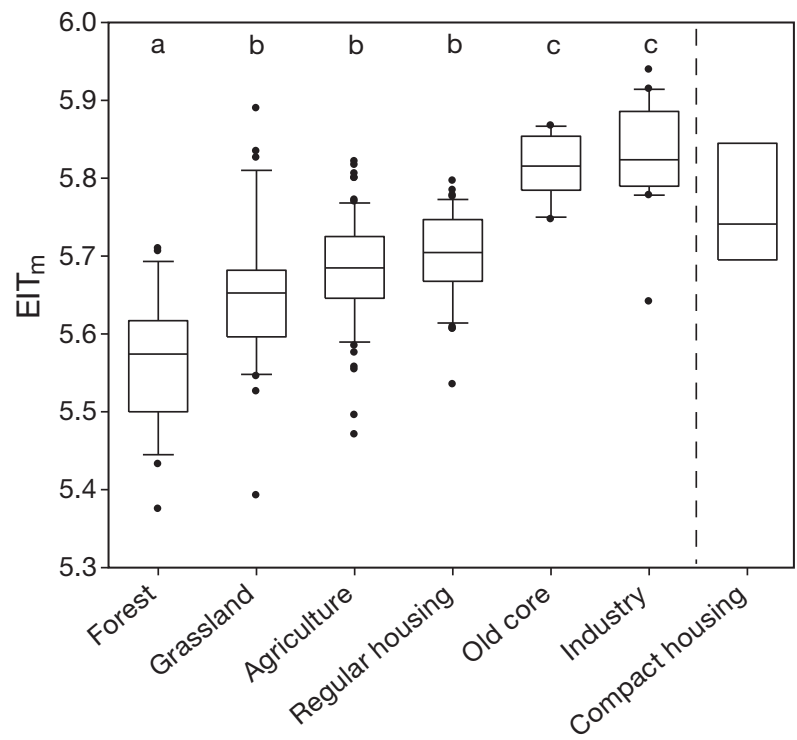

Fig. 3. Mean Ellenberg indicator values for temperature $\left(E_{\mathrm{m}}\right)$ for different local climate zones (LCZs). Plots show the median (central line), interquartile range (box), whiskers $\left(90^{\text {th }}\right.$ and $10^{\text {th }}$ percentiles) and outliers (dots). Letters indicate significant differences (ANOVA $\mathrm{p}<0.05$ ) between $\mathrm{EIT}_{\mathrm{m}}$ of the local climate zones (Tukey HSD). The LCZ 'compact housing' is shown but not included in the analysis due to limited sample size

towards the periphery and therefore agrees with conceptual UHI models.

The areas close to the water bodies (e.g. the river island in the west) and in the wetlands southeast of

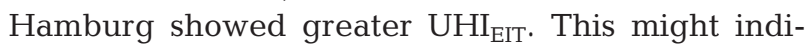
cate that the species composition expressed in the EIT is not only sensitive towards mean but also towards minimum air temperatures. However, the station in Kirchwerder also showed a mean UHI of $0.69 \mathrm{~K}$. This might be a bias of the reference station chosen by Schlünzen et al. (2010) but could also partly be attributed to the river, which is heat contaminated by a nuclear power plant nearby.

Overall, it can be stated that EITs contain substantial information about the mean heat island and that their application as a proxy is reasonable. However, the species distribution is determined by various ecological factors which also influence the EITs. Consequently, it cannot be determined to which degree a specific value is influenced by further factors, and the results must be evaluated carefully. If, as in Hamburg, no measurements with high spatial coverage are available, the EITs at least represent some picture of the spatial variation of the long-term UHI. This particularly applies to the spatial pattern but only with some restrictions to the absolute numbers. 


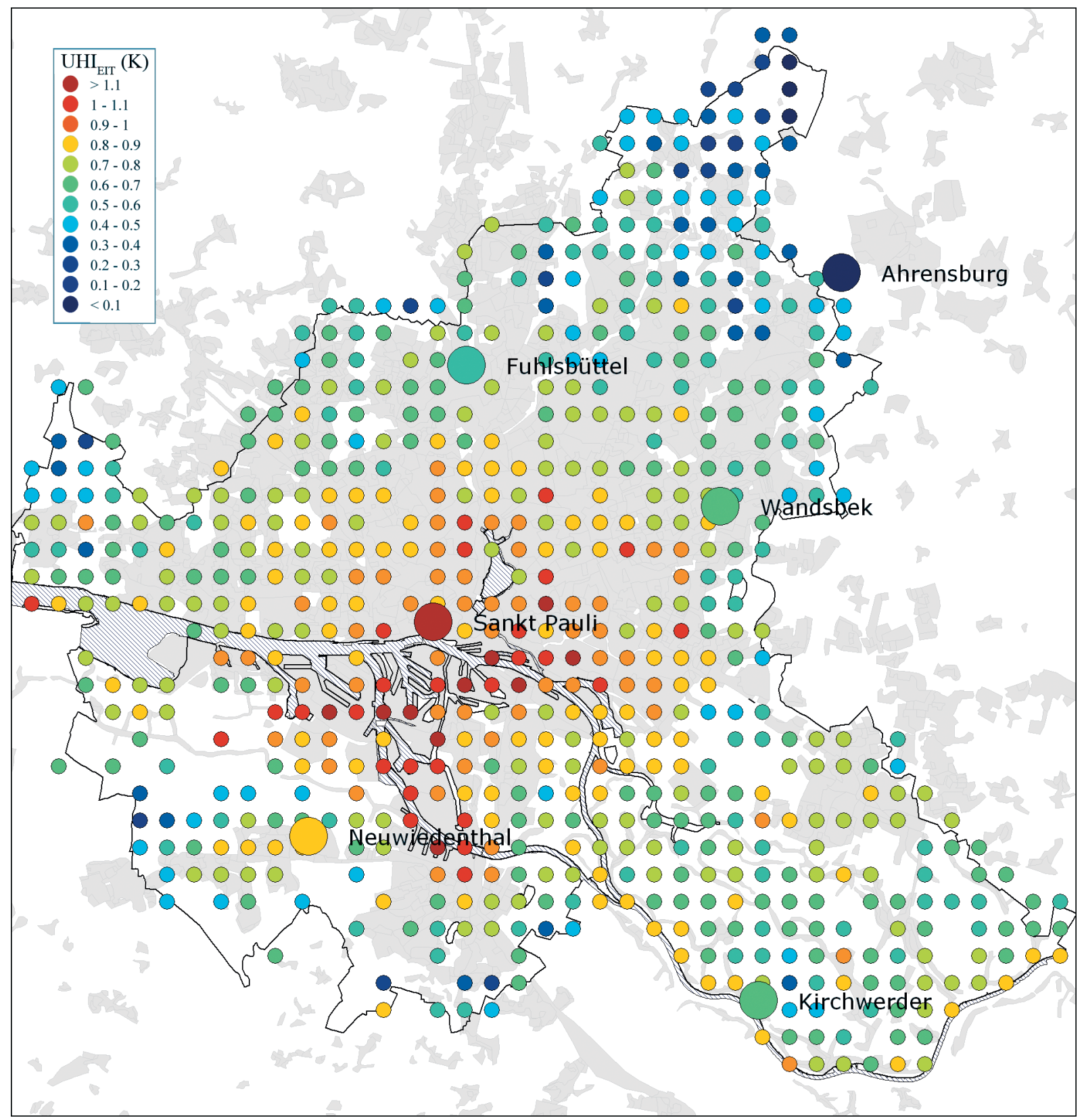

Fig. 4. Mean heat island intensity for Hamburg, Germany, derived from mean Ellenberg indicator values for temperature $\left(\mathrm{UHI}_{\mathrm{EIT}}\right)$. Large circles: values measured by Schlünzen et al. (2010); small circles: predicted values on a $\mathrm{km}^{2}$ raster

\subsection{Test of UHI predictor suitability}

Table 3 shows the pattern correlation results for chosen predictors. Correlations for SLOPE are not significant. All other correlations are highly significant $(\mathrm{p}<0.001)$. The remotely sensed predictors 'radiance at the top of the atmosphere' $\left(\mathrm{L}_{\mathrm{TOA}}\right), \mathrm{T}_{\mathrm{s}}$ and NDVI show a strong correlation with the derived $\mathrm{UHI}_{\text {EIT }}$ (i.e. $\mathrm{EIT}_{\mathrm{m}}$ ). The pattern correlation for selected scenes is 0.67 for $\mathrm{L}_{\mathrm{TOA}}$ and $\mathrm{T}_{\mathrm{s}}$ (scene no. 2:
Landsat Scene Identifier LE71950232001131EDC00) and -0.76 for NDVI (scene no. 1: Landsat Scene Identifier LE71950231999254EDC00). Since the results of $\mathrm{EIT}_{>5}$ are comparable, errors due to the averaging of ordinal numbers can be excluded. The better performance of NDVI is in accordance with Gallo et al. (1993) and Gallo \& Owen (1999), although their results become more differentiated when looking at a monthly time scale. The results of the selected scenes are not representative and are expected to 
Table 3. Pattern correlation of different predictors (by category) with the urban heat island derived from Ellenberg indicator values by linear regression (UHI $\mathrm{EIT}_{\mathrm{T}}$ ) and percentage of thermophilic plants with Ellenberg indicators $>5$ (EIT $>5$ ). NDVI: normalised difference vegetation index; $\mathrm{L}_{\text {TOA }}$ : radiance at the top of the atmosphere; TIR: thermal infrared; DMSP/OLS: Defense Meteorological Satellite Program/Operational Linescan System; SRTM: NASA Shuttle Radar Topography Mission data. All correlations are highly significant, except SLOPE (not significant). Square brackets: landscape scene identifier of respective scene

\begin{tabular}{|lrll|}
\hline Predictor & UHI $_{\mathrm{EIT}}$ & $\mathrm{EIT}_{>5}$ & Description \\
\hline Remote sensing & & & \\
NDVI & -0.761 & -0.743 & NDVI [LE71950231999254EDC00] \\
$\mathrm{L}_{\mathrm{TOA}}$ & 0.673 & 0.675 & TIR radiance [LE71950232001131EDC00] \\
$\mathrm{T}_{\mathrm{s}}$ & 0.675 & 0.677 & Surface temp. [LE71950232001131EDC00] \\
YAST & 0.647 & 0.648 & Yearly amplitude of surface temperature \\
$\mathrm{MAST}$ & 0.556 & 0.565 & Mean annual surface temperature \\
$\mathrm{L}_{\mathrm{TOA}}$ & 0.644 & 0.645 & TIR radiance [LT51950232007124MOR00] \\
$\mathrm{T}_{\mathrm{S}} \varepsilon=0.98$ & 0.645 & 0.646 & Surface temperature with constant emissivity/epsilon [same scene] \\
$\mathrm{T}_{\mathrm{S}}$ MOD $\varepsilon$ & 0.652 & 0.653 & Same as above description, with MODIS emissivity [MOD11A2 v.5] \\
NIGHTLIGHT & 0.504 & 0.490 & Nightime city light (DMSP/OLS) \\
Urban morphology, position $\&$ population & \\
WATERSHARE & 0.393 & 0.358 & \% of waterbodies \\
SOILSEAL & 0.540 & 0.546 & Soil sealing \\
BUILDDENS & 0.509 & 0.520 & Building density \\
GFZ & 0.410 & 0.412 & Floor space index \\
DIST2CEN & -0.597 & -0.579 & Distance to center \\
DIST2MWB & -0.653 & -0.648 & Distance to major water bodies \\
ALTITUDE & -0.361 & -0.358 & Above sea level from SRTM \\
SLOPE & -0.057 & -0.065 & \\
ASPECT & -0.101 & -0.089 & \\
POPDENS & 0.257 & 0.263 & Population density \\
a One or 2 cells excluded & & \\
& & & \\
\hline
\end{tabular}

change with season and atmospheric conditions. Therefore, the pattern correlations of different scenes are compared in the following section. The regression results for the selected scenes are shown in Fig. 5a,b.

To analyse the influence of differential emissivity, the surface temperature for a single scene (no. 3: Landsat Scene Identifier LT51950232007124MOR00) was calculated with constant emissivity and with spatially differentiated emissivity from a MOD11A2 dataset from the same date. The surface temperatures with differential emissivity show only a negligible improvement in explanation of $\mathrm{UHI}_{\mathrm{EIT}}$, which does not justify the additional effort.

The parameters for the yearly cycle are also well correlated with $\mathrm{UHI}_{\mathrm{EIT}}$, but less than the best single scene. Thereby, the amplitude of the yearly cycle performs better than the mean surface temperature. Hence, the multitemporal approach seems suitable to derive material properties of surfaces (the correlation $\mathrm{R}$ between YAST and SOILSEAL is 0.81).

The smaller correlation of MAST compared to $\mathrm{T}_{\mathrm{s}}{ }^{\text {(no.2) }}$ can be related to single scenes with different patterns, which are assumed to be contaminated by cirrus uncinus clouds. Fig. 6 shows the pattern correlation of $\mathrm{L}_{\mathrm{TOA}}$ of all scenes with the $\mathrm{UHI}_{\mathrm{EIT}}$ pattern, and clearly indicates that some scenes perform much worse than the average. This is not the case for NDVI where all scenes (except a single scene, which has obvious cloud contamination and should have been excluded) have an absolute $\mathrm{R}$ of more than 0.64. Two main reasons may account for this. Firstly, thin cirrus clouds have a smaller impact on visible transmission than on thermal emission, and secondly, the band ratio in the NDVI partly compensates for differential atmospheric conditions as stated above. Surprisingly, NDVI pattern correlations do not show strong seasonal variation, but this changes if a higher resolution and all Landsat 7 scenes are selected. Furthermore, all NDVI patterns show strong correlations with $\mathrm{T}_{\mathrm{s}}^{\text {(no.2) }}(+)$ of about -0.8 . In contrast, many of them agree less with the $\mathrm{L}_{\mathrm{TOA}}$ patterns of the same scene at the time of acquisition. This again is especially the case for the presumably cloud-contaminated scenes. To summarise, NDVI was observed to be more robust and therefore more suitable as a longterm UHI predictor, while for surface temperature, scenes with very clear and homogenous atmospheric conditions are especially suitable.

The urban morphology parameters show a varying picture, but SOILSEAL and BUILDDENS show pattern correlations of more than 0.5 . The floor-space 

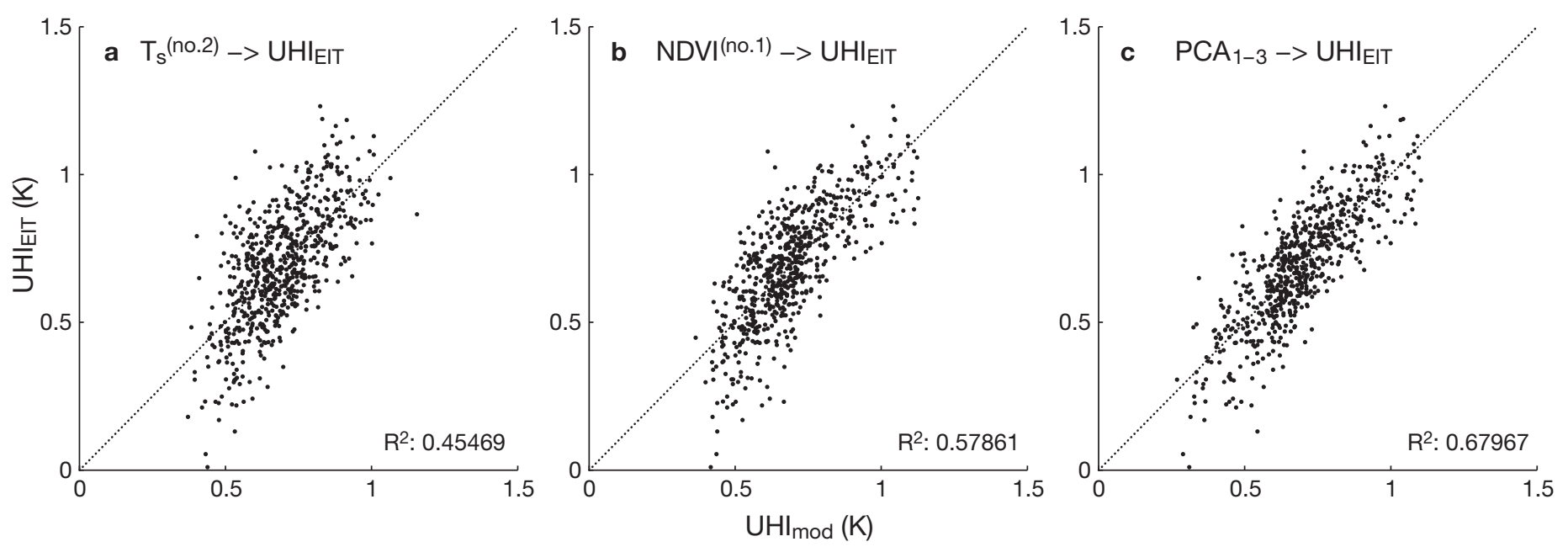

Fig. 5. Modelled urban heat island ( $\mathrm{UHI}_{\bmod }, \mathrm{x}$-axis) of different linear regression models against values from floristic proxy data $\left(\mathrm{UHI}_{\mathrm{EIT}}, y\right.$-axis) in Kelvin. Predictors used: (a) Surface temperature $\mathrm{T}_{\mathrm{s}}{ }^{(\mathrm{no.2})}$, (b) normalised difference vegetation index NDVI ${ }^{(\text {no.1) }}$, (c) first 3 principal components of 13 predictors PCA $_{1-3}$

index shows a correlation of 0.41 , and WATERSHARE has a correlation R of 0.39 .

Regarding the location in the city, $\mathrm{UHI}_{\mathrm{EIT}}$ is negatively correlated with both patterns, DIST2CEN and DIST2MWB. In principle, this is not surprising considering the partially radial shape of the city. However, the higher correlation with DIST2MWB also includes the higher EITs at the river that were discussed above. The altitude shows a negative correlation of only 0.36 . This is as expected regarding the rather flat topography. SLOPE and ASPECT show very weak correlations, which partly excludes errors from differential solar radiation.

NIGHTLIGHT turned out to be too smooth to show inner urban differences on a kilometre scale while it is very well correlated with DIST2CEN ( $\mathrm{R}=-0.79)$. However, it still performed almost as well as building density and is certainly sufficient to define a threshold for rural areas. Oppositely, population density was too specific on a kilometre scale, since many built-up areas (like the harbour or commercial centres) have no or only few inhabitants.

Since the predictors are highly redundant, the linear partial correlation coefficients between pairs of predictor variables controlling for $\mathrm{EIT}_{\mathrm{m}}$ were checked. As expected, partial correlations between $\mathrm{T}_{\mathrm{S}}, \mathrm{L}_{\mathrm{TOA}}$ as well as YAST and MAST are very high (e.g. $\mathrm{T}_{\mathrm{s}}^{\text {(no.2) }}$ and
YAST/MAST each 0.86). The morphology parameters SOILSEAL and BUILDDENS also show a high partial correlation (0.85). Also not surprisingly, NIGHTLIGHT and DIST2CEN show a strong negative partial correlation of -0.71 . On the other hand, DIST2MWB, WATERSHARE and ALTITUDE are quite independent.

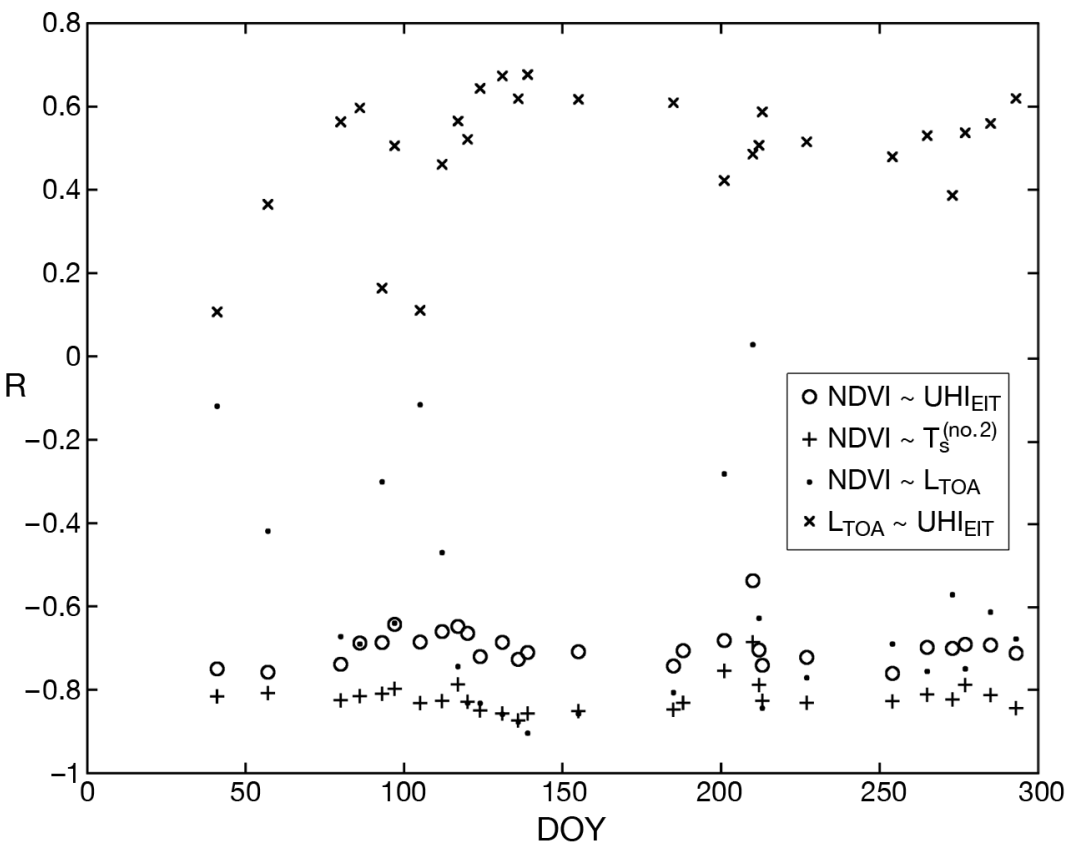

Fig. 6. Pattern correlations of remote sensing parameters for different scenes in the order of their acquisition time (day of year, DOY). ( $\times$ ), (O): Correlation of the floristic heat island pattern $\mathrm{UHI}_{\mathrm{EIT}}$ (urban heat island derived from Ellenberg indicator values) with thermal radiance $\left(\mathrm{L}_{\mathrm{TOA}}\right)$ and normalised difference vegetation index (NDVI), respectively, of a scene acquired on that day. (+) Correlation of the NDVI of this scene with the surface temperature of scene no. $2\left(\mathrm{~T}_{\mathrm{s}}^{(\text {no. } 2)}\right)$. $(\bullet)$ Correlation between $\mathrm{L}_{\mathrm{TOA}}$ and the NDVI of the same scene 
In the multiple regression of the principal components of 13 predictors, the first 3 principal components explained $68.0 \%$ of the variance in the $\mathrm{UHI}_{\mathrm{EIT}}$ (cf. Fig. 5c); the first 5 components explained $68.7 \%$, and all chosen predictors together $70.1 \%$. This agreement underpins that there is a relevant relation between the predictors und the 'floristic' heat island as well as the redundancy in the dataset.

\subsection{Discussion of the predictor suitability}

The overall high coherence with the 'floristic' heat island can be seen as a further proof of relevant information in the proxy data, although it cannot exactly be attributed to air temperature at a certain height. Gödde \& Wittig (1983, p. 261) stated that 'congenial organisms such as plants may be better indicators [for human well-being] than non-animated mercury or alcohol columns [...] - although they do not give exact figures'. This indicates the important fact that air temperature alone is insufficient to assess biometeorological impacts. Therefore, all meteorological parameters influencing the human energy balance need to be considered, most importantly the mean radiant temperature (Mayer et al. 2008).

On the other hand, the comparison of UHI predictors can also be seen as a contribution to an empirical analysis of the underlying factors of the UHI, or as Hart \& Sailor (2009, p. 398) put it, whilst 'the general causes of the urban heat island are well known, it is not well understood how much influence different urbanization characteristics (e.g. land-use, road density, vegetation coverage) have on the intensity of the UHI'. Deeper understanding of this influence would also contribute to improve urban surface parameters in order to develop 'more fundamental surface descriptors' (Voogt \& Oke 2003, p. 370), which should be more comprehensive and physically linked to the relevant surface-atmosphere exchange processes. Likewise, such an understanding of the underlying factors would address the question that was posed by Martilli (2007, p. 1913): 'how much complexity is necessary [...] to have a satisfactory representation of urban areas (or, in other words, which are the most important urban parameters that define a city)'.

However, for the empirical development of such fundamental surface descriptors, the given database is not sufficient. Even if the floristic data were shown to contain relevant information about the innerurban air temperature distribution, it is 'important to keep in mind that gradients of indicator values are still floristic gradients, even if the original floristic in- formation is transformed' (Schmidtlein 2005, p. 971). Therefore, the analysis should be complemented with 'real' measured data, which certainly are more credible in a quantitative sense.

\section{CONCLUSIONS AND OUTLOOK}

In this paper we introduced Ellenberg indicator values derived from inner urban distributions of spontaneously occurring vascular plant species as a UHI proxy. We tested their suitability as a proxy for long-term spatial inner urban air temperature distributions with very good results. This is in agreement with conceptual heat island models as well as the available climatic measurements and shows a pattern correlation of 0.89 with measured decadal mean UHI, although only 5 stations are available. Furthermore, the LCZs within the city show significantly different EITs. Therefore, EITs of a comprehensive floristic mapping can be used to generate a longterm mean heat island pattern, $\mathrm{UHI}_{\mathrm{EIT}}$, from floristic data. Although such a pattern is certainly influenced by additional factors, it can give a valuable estimation about the spatial distribution of heat-related risks within an urban area. However, the method will probably not become operational in urban climatology because of the large effort of the floristic mapping as well as the limited representativeness, which should be examined further. Nevertheless, from our point of view the pattern given in this study represents the best available inner-urban differentiation of the long-term UHI for Hamburg.

Furthermore, we compared the floristic heat island pattern with a large number of common predictors (mostly remote sensing and urban morphology data) in UHI studies. The remotely sensed parameters explained more of the spatial variation in $\mathrm{UHI}_{\mathrm{EIT}}$ than the urban morphological parameters, with an explained variance of up to $58 \%$ for a single parameter. NDVI was very robust, while for surface temperature, scenes with very clear and homogenous atmospheric conditions were particularly strongly correlated with the UHI $\mathrm{EIT}_{\mathrm{T}}$ pattern. Regarding the urban morphology, BUILDDENS and SOILSEAL had relevant correlations. Moreover, the position within the city (i.e. the distance to major water bodies) played a notable role, which might reflect the sensitivity of the plant species composition not only to mean but also to minimum air temperatures. These high correlations further prove that the proxy dataset comprises spatial information about the long-term heat island. 
On the other hand, several predictors showed a relevant pattern correlation with the 'floristic' mean UHI. Therefore, the predictors can also be considered applicable for (at least qualitative) assessment of inner-urban UHI and exposure to heat-related risks. To further evaluate their capacity to deliver quantitative UHI information, the consistent comparison of predictors should be continued with measured data at different scales. Therefore, a mobile measurement campaign with high spatial coverage and an integrated database of available measurements are being planned. The yearly cycle in surface temperature could potentially be used to determine specific material properties of the surface, such as heat conductivity and heat storage, and to classify LCZs, which we will examine further.

Acknowledgements. We thank the Regionalstelle für Pflanzenartenschutz, the Botanischer Verein zu Hamburg e.V. and especially H.H. Poppendieck for providing the data on plant species distribution, which was mapped voluntarily. We also thank C. Daneke for the LCZ data, P. Hoffmann and K. H. Schlünzen for the station UHI data as well as all further data providers for the UHI predictors. For their valuable comments on the manuscript we especially thank S. Bakan, M. Bock, J. Böhner and K. Jensen. The work was funded by the cluster of excellence CliSAP and partly funded by the BMBF within the research project KLIMZUG-NORD (grant number 01LR0805D). Further, we thank the reviewers for their comprehensive and constructive remarks on the first manuscript, which helped to substantially improve the paper.

\section{LITERATURE CITED}

Alcoforado MJ, Andrade H (2006) Nocturnal heat island in Lisbon (Portugal): main features and modelling attempts. Theor Appl Climatol 84:151-159

Balázs B, Unger J, Gál T, Sümeghy Z, Geiger J, Szegedi S (2009) Simulation of the mean urban heat island using 2d surface parameters: empirical modelling, verification and extension. Meteorol Appl 16:275-287

Barsi JA, Barker JL, Schott JR (2003) An atmospheric correction parameter calculator for a single thermal band earth-sensing instrument. International Geoscience and Remote Sensing Symposium 2003 (IGARSS '03). Proc 2003 IEEE Int 5, p 3014-3016

Barsi JA, Schott JR, Palluconi FD, Hook SJ (2005) Validation of a web-based atmospheric correction tool for single thermal band instruments. In: Butler JJ (ed) Earth Observing Systems X. Proc SPIE 58820:1-7 doi: 10.1117/ 12.619990

Bechtel B (2011) Multitemporal Landsat data for urban heat island assessment and classification of local climate zones. Joint Urban Remote Sensing Event. Proc 2011 IEEE Int, p 129-132

Böhner J, Blaschke T, Montanarella L (eds) (2008) SAGA seconds out. Hamburger Beiträge zur Physischen Geographie und Landschaftsökologie 2. Geographisches Institut der Universität Hamburg

Borgefors G (1986) Distance transform in digital images.
Comput Vis Graph Image Process 34:344-371

Bottyán Z, Kircsi A, Szegedi S, Unger J (2005) The relationship between built-up areas and the spatial development of the mean maximum urban heat island. J Climatol 25: 405-418

Buttstädt M, Sachsen T, Ketzler G, Merbitz H, Schneider C (2010) Urban temperature distribution and detection of influencing factors in urban structure. International Seminar on Urban Form 2010, Hamburg. Available at www.isuf2010.de/Papers/Buttstaedt_Mareike.pdf

Chander G, Markham BL, Helder DL (2009) Summary of current radiometric calibration coefficients of Landsat MSS, TM, ETM+ and EO-1 ALI sensors. Remote Sens Environ 113:893-903

Daneke C, Bechtel B, Langkamp T (2010) Classification scheme of urban structures based on climatic characteristics, designed for land use modeling applications. International Seminar on Urban Form 2010, Hamburg. Available at www.isuf2010.de/Papers/Daneke_Christian.pdf

$>$ Eliasson I (1992) Infrared thermography and urban temperature patterns. Int J Remote Sens 13:869-879

Ellenberg H, Weber E, Düll R, Wirth W, Werner W, Paulißen D (1992) Zeigerwerte von Pflanzen in Mitteleuropa, 2nd edn. Scripta Geobotanica 18, Verlag Erich Goltze KG, Göttingen

Ewald J (2003) The sensitivity of Ellenberg indicator values to the completeness of vegetation relevés. Basic Appl Ecol 4:507-513

Franken E (1955) Der Beginn der Forsythienblüte 1955 in Hamburg, ein Beitrag zur Phänologie der Großstadt. Meteorol Rundsch 8:113-114

> Gallo KP, Owen TW (1998) Assessment of urban heat islands: a multi-sensor perspective for the Dallas-Ft. Worth, USA region. Geocarto Int 13:35-41

Gallo KP, Owen TW (1999) Satellite-based adjustments for the urban heat island temperature bias. J Appl Meteorol 38:806-813

> Gallo KP, McNab AL, Karl TR, Brown JF, Hood JJ, Tarpley JD (1993) The use of NOAA AVHRR data for assessment of the urban heat island effect. J Appl Meteorol 32: 899-908

> Gödde M, Wittig R (1983) A preliminary attempt at a thermal division of the town of Münster (North RhineWestphalia, West Germany) on a floral and vegetational basis. Urban Ecol 7:255-262

> Godefroid S, Koedam N (2007) Urban plant species patterns are highly driven by density and function of built-up areas. Landscape Ecol 22:1227-1239

Hansen J, Ruedy R, Sato M, Lo K (2010) Global surface temperature change. Rev Geophys 48:RG4004. doi:10.1029/ 2010RG000345

Hart MA, Sailor DJ (2009) Quantifying the influence of landuse and surface characteristics on spatial variability in the urban heat island. Theor Appl Climatol 95:397-406

Imhoff ML, Lawrence WT, Elvidge CD, Paul T, Levine E, Privalsky MV, Brown V (1997) Using nighttime DMSP/OLS images of city lights to estimate the impact of urban land use on soil resources in the United States. Remote Sens Environ 59:105-117

> Karl TR, Diaz HF, Kukka G (1988) Urbanization: its detection and effect in the United States climate record. J Clim 1: 1099-1123

Klotz S, Kühn I, Durka W (2002) Bioflor- eine Datenbank mit biologisch-ökologischen Merkmalen zur Flora von Deutschland. Schriftenr Vegetationskd 38:1-334 
Kuttler W, Barlag AB, Rossmann F (1996) Study of the thermal structure of a town in a narrow valley. Atmos Environ 30:365-378

Landsberg HE (1981) The urban climate. Academic Press, New York

Lowry WP (1977) Empirical estimation of urban effects on climate: a problem analysis. J Appl Meteorol 16:129-135

Martilli A (2007) Current research and future challenges in urban mesoscale modelling. Int J Climatol 27:1909-1918

Matzarakis A (2001) Die thermische Komponente des Stadtklimas. Berichte des Meteorologischen Institutes der Universität Freiburg 6, Freiburg

Mayer H, Holst J, Dostal P, Imbery F, Schindler D (2008) Human thermal comfort in summer within an urban street canyon in Central Europe. Meteorolog Z 17: 241-250

McKinney ML (2002) Urbanization, biodiversity, and conservation. Bioscience 52:883-890

Nichol EJ, Fung WY, Lam KS, Wong MS (2009) Urban heat island diagnosis using ASTER satellite images and 'in situ' air temperature. Atmos Res 94:276-284

Oke TR (1973) City size and the urban heat island. Atmos Environ 7:769-779

Oke TR (1988) The urban energy balance. Prog Phys Geogr 12:471-507

Oßenbrügge J, Bechtel B (2010) Klimawandel und Stadt der Faktor Klima als neue Determinante der Stadtentwicklung. In: Böhner J, Ratter BMW (eds) Klimawandel und Klimawirkung. Hamburger Symposium Geographie 2. Institut für Geographie der Universität Hamburg

Parker DE (2010) Urban heat island effects on estimates of observed climate change. Wiley Interdiscip Rev Clim Change 1:123-132

Petř́k P, Wild J (2006) Environmental correlates of the patterns of plant distribution at the meso-scale: a case study from northern Bohemia (Czech Republic). Preslia 78: 211-234

Poppendieck HH, Brandt I, von Prondzinski J, Kreft KA (2002) Artenkataster Hamburg im Spannungsfeld von staatlicher Aufgabe und ehrenamtlichen Engagement. Schriftenr Vegetationskd 36:69-77

Editorial responsibility: Helmut Mayer, Freiburg, Germany
Poppendieck HH, Bertram H, Brandt I, Engelschall B, von Prondzinski J (2010) Der Hamburger Pflanzenatlas von A bis Z. Dölling \& Galitz Verlag, München

Pyšek P (1998) Alien and native species in central European urban floras: a quantitative comparison. J Biogeogr 25: 155-163

Reidat R (1971) Temperatur, Niederschlag, Staub. Deutscher Planungsatlas. Band VIII. Hamburg, Lieferung 7 . Gebrüder Jänecke, Hannover

Rosenhagen G, Schatzmann M (2011) Das Klima der Metropolregion auf Grundlage meteorologischer Messungen und Beobachtungen. In: von Storch H, Claussen M (eds) Klimabericht für die Metropolregion Hamburg. Springer, Berlin, p 19-60

$>$ Roth M, Oke TR, Emery WJ (1989) Satellite-derived urban heat islands from three coastal cities and the utilization of such data in urban climatology. Int J Remote Sens 10: 1699-1720

Santer BD, Wigley TML, Jones PD (1993) Correlation methods in fingerprint detection studies. Clim Dyn 8:265-276

Schlünzen KH, Hoffmann $\mathrm{P}$, Rosenhagen G, Riecke W (2010) Long-term changes and regional differences in temperature and precipitation in the metropolitan area of Hamburg. Int J Climatol 30:1121-1136

Schmidtlein S (2005) Imaging spectroscopy as a tool for mapping Ellenberg indicator values. J Appl Ecol 42: 966-974

> Souch C, Grimmond S (2006) Applied climatology: urban climate. Prog Phys Geogr 30:270-279

Stewart ID, Oke TR (2009) Newly developed 'thermal climate zones' for defining and measuring urban heat island magnitude in the canopy layer. T.R. Oke Symp \& 8th Symp Urban Environ, January 11-15, Phoenix, AZ

Voogt JA, Oke TR (2003) Thermal remote sensing of urban climates. Remote Sens Environ 86:370-384

Wong MS, Nichol J, Kwok KH (2009) The urban heat island in Hong Kong: causative factors and scenario analysis. Joint Urban Remote Sensing Event 2009. Proc IEEE Int, p 1-7

Yokobori T, Ohta S (2009) Effect of land cover on air temperatures involved in the development of an intra-urban heat island. Clim Res 39:61-73

Submitted: December 13, 2010; Accepted: April 19, 2011 Proofs received from author(s): September 12, 2011 